
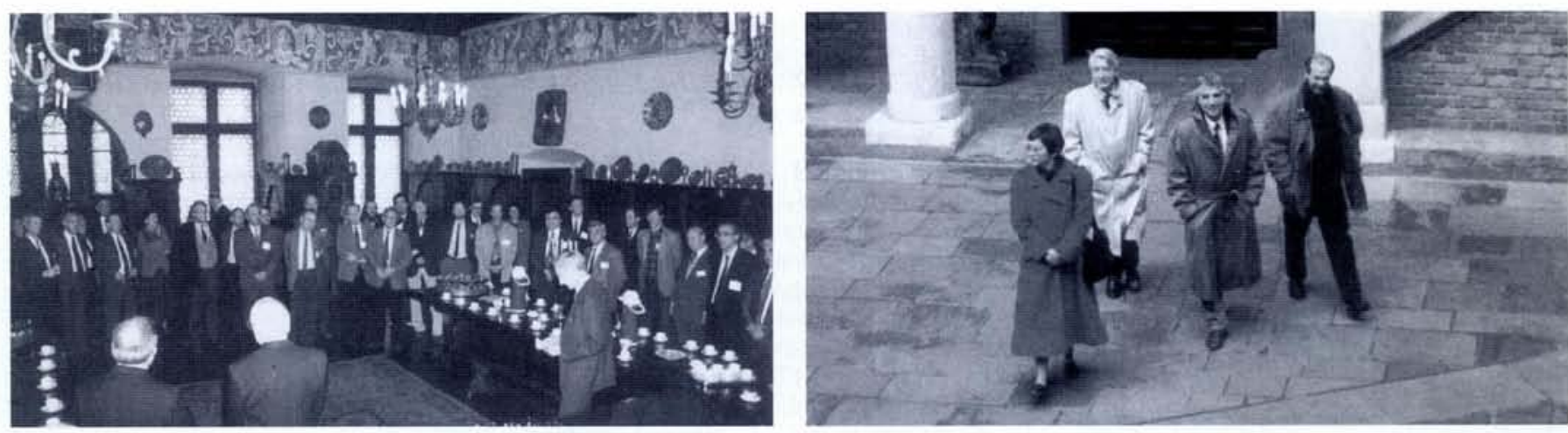



Upper left, Professor Aleksander Koj, the Rector of Jagiellonian University welcoming Council delegates to the Jagiellonian Museum housed in the 15th century Collegium Maius. Upper right: Malgorzata Godlewska on the left, who helped organize Council, with P.K. Carrol, W. Heinicke and J. Mlynek in the courtyard of the Collegium Maius. Lower. $T$. Henriksen (centre), who gave a special lecture of biophysics, with $R$. Hellborg (on the left) and $E$. Osnes.

- IOMs \& Associate Members: 12 each

- National societies:

46

- Divisions/Groups:

Representation is thus fairly well equilibrated for "corporate" votes (the Divisions and the NS), while the "individual" votes of the IOMs and Associates are able to tip the balance. C.A.P. Foxell pointed out that the equilibrium could be displaced as the Divisions grow in size. One can estimate that a uniform doubling, for example, of membership across the Divisions and the NS from today's levels would increase the NS vote to about 50 and the Division vote to about 60 . It may then be wise to consider readjusting voting rights.

For votes involving the unit fee, the various categories of Individual Ordinary Members (IOMs) have between 4 and 8 votes. The NS are now entitled to vote according to their declared memberships at the rate of one unit per full member, with percentages of the unit for their other categories. This reflects the willingness of NS to contribute according to the same scale independent of their size. The Divisions have no voting rights because these are considered to be included in the NS and IOM rights. For reasonable assumptions regarding the number of IOMs given that members of national societies can participate as NSMs in Division activities, the estimated numbers of votes under the revised Constitution are:

$$
\begin{array}{ll}
\text { - NS: } & 51300 \\
\text { - IOMs: } & 7300-10300
\end{array}
$$

with the German and UK societies, by far the largest, holding about 23000 votes. Changing the unit fee needs the support of three-quarters of the votes cast.

\title{
National Society Member Category Created
}

Members of national physical societies can belong to EPS Divisions following Council's acceptance of a new membership category.

Seen by the EPS President, Norbert Kroó, as an historic point in the Society's evolution, the decision by the EPS Council meeting in Cracow on 25-26 March to accept a revised EPS Constitution and By-laws will enable individual members of national physical societies to join EPS Divisions and Groups. It was, to all appearances, voted in unanimously by a show of hands after Council agreed that a closed ballot in two steps (since proposals affected both the Constitution and the membership unit fee) was unnecessarily complicated given the vote's significance.

\section{National Society Members}

The Society had hoped to go somewhat further by allowing members of national societies to become full members of EPS under a revised Article 4 of the Constitution (they would then be called National Society Members or NSMs). The version of the revised Constitution and By-laws sent to EPS members last November for comment was drafted accordingly. The ensuing discussions together with legal advice confirmed an important limitation, namely that under international law a person cannot become a member of an association such as EPS without his or her consent in writing. The
Executive Committee's working group (composed of Hans Beck, Walter Merz, George Morrison, and Gero Thomas) which was charged with formulating the revisions therefore decided to enable individual members of national societies which belong to EPS to participate in the activities of the EPS Divisions and Interdivisional Groups as NSMs. A new Article (No. 7) was added and Rule No. 29 (Division membership) of the By-laws extended to include NSMs (see below). The NSMs join the national societies and the Associate Members in having voting rights (specified in a revised Rule 11) in the General Meeting, the Society's highest authority.

Council decided that it was unnecessary to submit the final changes to members as they did not concern the substance of the proposals. Such concerns illustrate the effort that has gone into identifying appropriate ways for physicists to interact and coordinate at the European level within a national framework.

\section{Implementation Later This Year}

Members of a national society which belongs to EPS are entitled to become NSMs as from 1 April 1994. They can sign up by writing to the Secretariat giving details

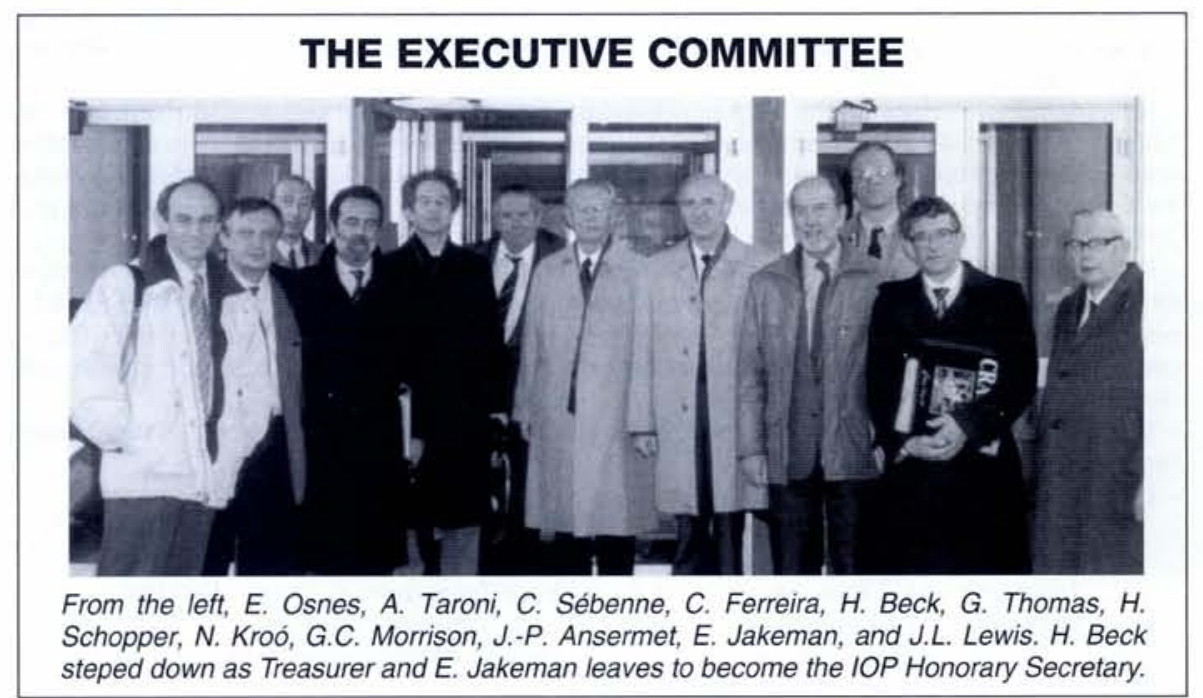





Upper, C. Sébenne, on the left, with J.-P. Ansermet from Lausanne who was elected to the Executive Committee. Lower, J.L. Lewis from Malvern, UK, who was elected as the new Treasurer.

such as their name, address, national society affiliation, and the Division or Group they wish to join. However, while there are no formal steps preventing implementation, it is probably wise to wait for an announcement later this year before applying. There will be some direct membership benefits even though NSMs will not need to pay a fee to EPS, but it is too early to specify them precisely as some will probably involve adjusting Division statutes.

\section{Fee Scale Adjusted}

The other main revision of the Constitution and By-laws accepted by Council concerns new arrangements for the unit fee. There were no changes in this regard compared with the version submitted to members. Starting on 1 January 1995, a national society belonging to EPS will pay one unit of fee per normal member and is responsible for distributing to these members Europhysics News delivered in bulk to the society. The exceptions are societies that ask EPS to distribute directly to NSMs against additional payment, and the two largest nationa societies - the UK's Institute of Physics and the German Physical Society - who

The final versions of Article 7 of the Constitution and Rule 29 of the Bye-laws as accepted by Council are as follows:

Article 7: Individual members of a nationa society which has been accepted as an Ordinary Member of EPS may participate in the activities of EPS according to Rules 11 and 29 as National Society Members even if they did not become Individual Ordinary Members of EPS.

Rule 29: Participation in the activities of a Division and/or Interdivisional Group shall be open to Individual Ordinary Members (IOMs) of the Society and to National Society Members (NSMs) according to Article 7 of the Constitution, who have stated to the EPS Secretariat their intention to be a member of a Division and/or Interdivisional Group.

\section{Decisions of EPS Council}

EPS Council at its meeting in Cracow on 25-26 March 1994 decided the following:

- Constitution and By-laws: To approve the revised Constitution and By-laws.

- 1994 budget: To approve the 1994 proposed budget envisaging a surplus of about 8 kFR.

- Membership arrears: To reduce all membership benefits and privileges to Member Organizations in default by amounts proportional to missing fee payments.

- Solidarity Fund: The creation of a Solidarity Find, subject to a review after three years, to promote the activities of Group, Sections and Divisions which have few resources. Administered by the Conference Committee, it will financed by $20 \%$ of a minimum levy of SFR 20.- on the conference registration fees of all participants except students, with the remaining $80 \%$ being transferred to the account of the organizing Group, Section or Division.

- EPS conferences: That conferences organized by EPS Groups, Sections and Divisions seek European Community support by including a Conference Committee endorsement highlighting EPS policies and facilities.

- New Members: To accept the Ukrainian Physical Society as a Member of EPS. To accept the Society of Physicists of the Republic of Macedonia as a Member of EPS subject to consultation among Members and a statement indicating that the Society will honour financial obligations. To accept two new Associate Members (Oracle Corp., UK Ltd.; John Wiley \& Sons, Ltd.) and 203 Individual Ordinary Members.

- Professional qualification: To approve the creation of a Register of European Physicists (Eur Phys) subject to a review after three years. The application fee will be a maximum of SFR 50.payable to the relevant Monitoring Committee and the registration fee will be SFR 250.decreasing to 175.- at the first renewal after 5 years, and to SFR 125.- for subsequent renewals for 5 years.

- Electronic services: To authorize the Executive Committee to consider the steps to be taken regarding electronic services.

- Elections to the Executive Committee:

President: N. Kroó, Budapest

Secretary: A. Taroni, Bresica

Treasurer: J.L. Lewis, Malvern

Members: A.F. Andreev, Moscow

C.M. Ferreira, Lisbon

C. van der Leun, Utrecht will receive EPS information and news as film for publication in their national bulletins.

A society may pay a reduced fee for special membership categories. It will be based on the amount an individual member pays to the society, but a copy of Europhysics News will not be supplied for these categories. Individual Ordinary Members of EPS will of course continue to receive Europhysics News directly from EPS and to enjoy the full range of privileges and benefits the Society offers. But perhaps more importantly. through their commitment it will be possible to further develop initiatives across a broad range of areas.

\section{Ukraine Joins EPS}

In presenting to Council the Ukrainian Physical Society's (UPS) application, which was accepted unanimously, to become an EPS member, Professor 1.O. Vakarchuk, Rector of Lviv University and Vice-President of the UPS, described how the UPS represents all of the country's research physicists and most institutes. There is a coordinating board (executive committee) comprising representatives of 42 regional physical societies and UPS branches from the entire country. Registered as a self-managed creative organization with sections for fundamental and applied physics and teaching, the UPS was formed in 1991 and now has 2470 individual members. There is a secretariat at the Physics Department, Kiev State University, and a monthly bulletin called Physical Messenger has been published since mid-1993. Professor Vakarchuk speaking on behalf of the President, Professor V.V. Eremenko, Director of the Institute of Low Temperature Physics and Engineering in Kharkov, said that the UPS valued EPS membership very highly and accepted all the obligations. The American Physical Society supported an UPS school on optics held in June 1993 and has provided journal subscriptions and emergency grants through the UPS. The UPS plans to hold 4 schools this year as the organization of regular meetings such as last year's international conference Physics in the Ukraine is a primary goal.

\section{PHYSICS IN THE UKRAINE}

The Ukraine has 52 million inhabitants and physics research is mainly carried out at Academy and ministry institutes located in the capital, Kiev (Physics, Semiconductor Physics, Theoretical Physics, Nuclear Theory, Nuclear Research, Problems in Materials Research, Mechanics Physics, Metal Physics), Kharkov (Low Temperature Physics and Engineering, Radioastronomy, Single Crystals), Uzhgorod (Electronics Physics), and Donetsk (Physical-Techical). Many of the country's 20 universities, polytechnics and pedagogical institutes that teach physics also perform research.

Further detailed information is available in the directory Physics in the Former Soviet Union, available as a Postscript file on the WorldWide Web in the EPS East-West Coordination Committee server at NIKHEF, Amsterdam. Logon to WWW with www and then follow the path cern - high energy physics labs nikhef - ewcc - databases.
President-Elect: H. Schopper, Geneve Vice-Treasurer: E. Osnes, Blindern

J.-P. Ansermet, Lausanne

G.C. Morrison, Birmingham 